\title{
Spotted fever group Rickettsia in brown dog ticks Rhipicephalus sanguineus in southwestern Spain
}

\author{
F. J. Márquez \& J. J. Rodríguez-Liébana \& \\ R. C. Soriguer \& M. A. Muniaín \& M. Bernabeu-Wittel \& \\ A. Caruz \& F. Contreras-Chova
}

\begin{abstract}
A total of 2,229 adults ticks (1,428 males and 801 females) belonging to the brown dog tick, Rhipicephalus sanguineus Latreille, 1806, collected from dogs in Seville province (Andalusia), distributed in 500 lots ranging from one to eight specimens per lot, were examined for the presence of rickettsiae by molecular techniques. Specific rickettsiae DNA were detected in 90 lots $(18 \%)$ of ticks tested. Sequence analysis of amplicons revealed that R.
\end{abstract}

F. J. Márquez ( ) : J. J. Rodríguez-Liébana

Dpto. Biología Animal, Biología Vegetal y Ecología,

Universidad de Jaén,

Campus Las Lagunillas s/n,

23071 Jaén, Spain

e-mail: jmarquez@ujaen.es

\section{R. C. Soriguer}

Estación Biológica Doñana, CSIC,

Pabellón del Perú,

41013 Seville, Spain

\section{A. Muniaín}

Hospital Universitario "Virgen Macarena",

Avd. Dr. Fedriani, 3,

41009 Seville, Spain

\section{Bernabeu-Wittel}

Servicio de Enfermedades Infecciosas,

Hospitales Universitarios "Virgen del Rocio",

Avda. Manuel Siurot s/n, 3,

41013 Seville, Spain

\section{A. Caruz}

Dpto. Biología Experimental, Universidad de Jaén, Campus Las Lagunillas s/n,

23071 Jaén, Spain

F. Contreras-Chova

Hospital Universitario "San Cecilio",

Avda. Doctor Oloriz 16,

18012 Granada, Spain sanguineus ticks were infected exclusively with Rickettsia massiliae (including the strain Bar-29). The results of this study extend the knowledge of the geographic distribution and prevalence of these spotted fever group (SFG) rickettsiae and indicate that at least two of them, with yet uncertain pathogenicity to humans, are present in brown dog ticks in south western Spain. Although Mediterranean spotted fever (MSF) is an endemic disease in Andalusia, Rickettsia conorii was not found, whereas R. massiliae, recently described as a pathogenic species, was highly prevalent in this area. Our data suggest that in Andalusia a number of MSF or MSF-like cases attributed to R. conorii could have been actually caused by other SFG rickettsia present in R. sanguineus, particularly, R. massiliae.

Introduction

In the Mediterranean area, some spotted fever group (SFG) rickettsiae have been implicated in human disease and are therefore defined as pathogenic species (Parola et al. 2005; Brouqui et al. 2007). These rickettsiae include Rickettsia conorii, the causal agent of Mediterranean spotted fever (MSF), comprising a variety of genospecies of R. conorii (Zhu et al. 2005), and several other tick-borne species of SFG that are considered scarcely or not pathogenic to humans, as Rickettsia massiliae (Beati and Raoult 1993; Vitale et al. 2006).

The epidemiology of rickettsiae and rickettsial diseases in Andalusia (south Iberian Peninsula) is not well known. Seroepidemiological studies have revealed the presence of SFG rickettsiae ( $R$. conorii, Rickettsia felis, and $\mathrm{R}$. massiliae) as well as Rickettsia typhi in western Andalusia (Bernabeu-Wittel et al. 2006a, b). The purpose of this study was to investigate, identify, and characterize SFG rickett- 
siae in brown dog ticks collected from dogs in Seville province. The particular feature of brown dog tick enables it to complete its entire life cycle indoors. Because of this, this tick can establish populations in colder climates and has been found in extensive areas of the world. Many tick species can be carried indoors by their animal hosts but cannot complete their entire life cycle inside. Although Rhipicephalus sanguineus feed on a wide variety of mammals, dogs are the preferred hosts in Andalusia and appear to be required to develop large infestations Millán et al. (2007). The transovarial and transtadial transmission of SFG rickettsiae within tick vectors in nature ensures rickettsial survival and determines their limited distribution to that of their tick vectors (Raoult and Roux 1997; Azad and Beard 1998; Parola et al. 2005).

Prevalence studies of infection in the tick vector can be used as an indicator of possible changes in the intensity of Rickettsia spp. transmission. However, these studies are difficult to carry out, as prevalence in vectors is usually low, and its estimation requires large number of ticks to be dissected.

Material and methods

\section{Sampling}

A total of 2,229 dog brown ticks (1,428 males and 801 females) were collected from 500 domestic dogs in urban and suburban areas from 89 different areas in Seville Province (western Andalusia, Spain) between April 1999 to March 2005. After collection, the ticks were immediately placed in vials with $70 \%$ ethanol, were properly labeled, and were later identified in the laboratory by species, gender, and stage by a professional entomologist using specific taxonomic keys (Walker et al. 2000).

\section{Methods}

Ticks were rinsed with distilled water, dried on sterile filter paper, and then crushed in sterile Eppendorf tubes. DNA was extracted from 500 pools of adult ticks (from one to eight specimens per pool, average of 4.46 ticks per pool) using the Macherey-Nagel DNA tissue Kit (Düren, Germany) according to the manufacturer's instructions. The efficiency of DNA extraction was verified in all samples by polymerase chain reaction (PCR) assay, which amplifies 12S ribosomal RNA (rRNA) of tick origin (Zahler et al. 1997; Bernasconi et al. 2002) as well as in the cases that doubt persisted in discrimination between $\mathrm{R}$. sanguineus and Rhipicephalus turanicus. Discrimination was made using an amplification of a fragment of mitochondrial 12S rRNA using the oligonucleotides T1B and T2A (Beati and Keirans 2001) and amplification conditions described elsewhere (Bernasconi et al. 2002). Negative controls consisted of distilled water extracted in the same laboratory. Specific rickettsial sequences were detected by using PCR primers that amplify a portion of glta, ompA, ompB, and 16S rRNA genes, respectively Márquez et al. (1998). Subsequent direct sequencing of amplified products was performed on selected samples in order to provide an objective and precise identification, using specific PCR primers and the Genome DTCS-quick Start kit (Beckman Coulter, Fullerton, CA, USA) in a capillary DNA sequencer CEQ 2000XL (Beckman Coulter).

Results and discussion

Overall, rickettsial DNA was detected in 90 (18\%) of the examined tick pools by PCR, amplifying at least two rickettsiae-specific fragments. Six of positive samples only amplified glta and ompA fragments. The alignment of ompB sequences obtained from the remaining 84 positive pools detected, in all the cases, two variants of R. massiliae (Beati and Raoult 1993). From a geographic point of view, positive samples were dispersed in Seville province and did not show a specific geographic distribution pattern (Fig. 1). Pools with infected ticks appeared in 49 of examined areas (55.06\%) with values ranging from $4 \%$ to $100 \%$ of processed samples.

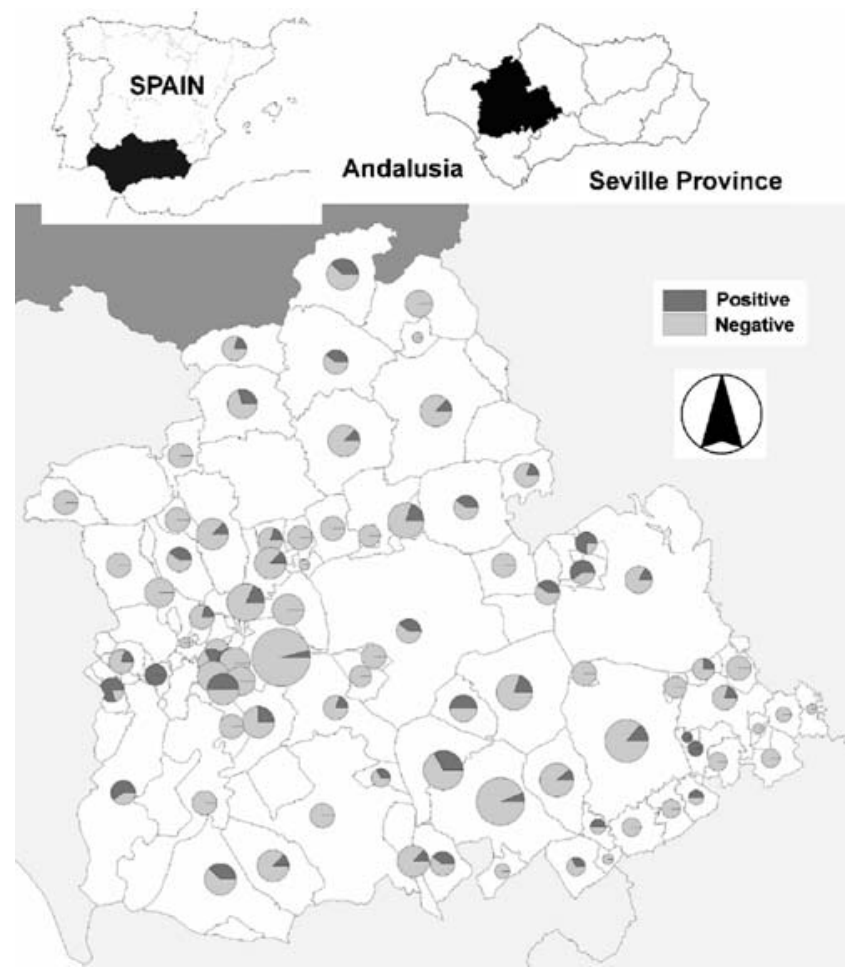

Fig. 1 Geographical distribution of R. massiliae positive ticks in Seville province. Diameter of circles is proportional of number of samples studied in each area 
Mediterranean spotted fever is well known to be endemic in the whole Iberian Peninsula (Herrero-Herrero et al. 1989; Cardeñosa et al. 2003, 2006; Bartolomé et al. 2005; Guerrero et al. 2006) and particularly western Andalusia (BernabeuWittel et al. 2006a, b). Nevertheless, to our knowledge, no studies evaluating the presence of Rickettsia spp. in ticks from domestic dog has been made yet in Andalusia.

The most striking finding of our study was the exclusive detection of R. massiliae (including Bar-29 strain), together with the absence of $\mathrm{R}$. conorii. R. massiliae has been detected in R. sanguineus and/or R. turanicus in France (Beati and Raoult 1993), Portugal (Bacellar 1999), Spain (Beati et al. 1996; Merino et al. 2005), Switzerland (Bernasconi et al. 2002), Greece (Psaroulaki et al. 2006), and Algeria (Bitam et al. 2006) and recently was signaled in the US (Eremeeva et al. 2006). Our results are in accordance with those obtained by Merino et al. (2005) and Fernández-Soto et al. (2006a). They studied 4,049 ticks removed from asymptomatic patients in Castilla-León (north western Spain) belonging to 14 ixodid and one argasid species; R. conorii was detected exclusively in a single specimen of R. sanguineus over a sample of $132 \mathrm{R}$. sanguineus and $388 \mathrm{R}$. turanicus. In contrast, R. massiliae was detected in $37 \mathrm{R}$. turanicus, six R. sanguineus, one Rhipicephalus pusillus, and 4 of 1,799 Ixodes ricinus Fernández-Soto et al. (2006a, b). In Portugal, Bacellar (1999) found a prevalence of SFG rickettsiae of $1.8 \%$ among 2,207 R. sanguineus tested for the presence of rickettsiae, from vegetation, dogs, and sylvatic mammals. Of 25 Rickettsia spp. Isolates, 22 were identified as $\mathrm{R}$. massiliae and three corresponded to R. conorii.

In Seville province, the absence of $\mathrm{R}$. conorii in $\mathrm{R}$. sanguineus ticks contrasts with the elevated seroprevalence (8.7\% globally) found recently in humans by BernabeuWittel et al. (2006a, b). The prevalence of R. massiliaeBAR29 past infections in the same population was 3.4\% (Bernabeu-Wittel et al. 2006b). In natural conditions, R. massiliae could be transmitted by several species of $\mathrm{R}$. sanguineus group (Matsumoto et al. 2005a, b). R. sanguineus is well adapted to human rural and urban environments, with an elevated specificity for canine hosts, mainly dogs. In usual conditions, despite the high prevalence of R. massiliae detected in the studied R. sanguineus, the risk of transmission to humans associated to the bite of this tick is low; in fact, these ticks feed on humans only when domestic or sylvatic canids are not available (or protected with tick repellents; Brouqui et al. 2007). Recently, R. massiliae has been confirmed as human pathogen, causing a disease that mimics entirely the clinical and biological features of MSF (Vitale et al. 2006). Hence, the exact etiologic agent of an unknown number of MSF or MSF-like cases, as well as the detected past human infections in our area, remains unclear. In this sense, future clinical studies specifically focused in the molecular detection of MSF etiology are needed to definitively answer this issue.

The above mentioned seroepidemiological study carried out recently by Bernabeu-Wittel et al. (2006a, b) in Andalusia indicated the possible existence of several SFG rickettsiae transmitted by ticks (R. conorii and R. massiliae sensu lato) or by flea (R. felis). The prevalence of past infections due to of R. massiliae-Bar29 and R. conorii in this region was highest in rural areas (about $10-11 \%$ ) with respect to suburban and urban areas, in oldest population segments (because of prolonged-repeated exposure time with respect to younger populations), in people with highrisk professions, and in those with close contact with various animal species (Bernabeu-Wittel et al. 2006b). These findings clearly reflect the close correlation between SFG rickettsiae past infections and the intensity of hostvector exposure.

In conclusion, our data show the presence of high $\mathrm{R}$. massiliae infection rates in brown ticks in south western Spain and a total absence of R. conorii. This, together with clinical and recent human seroprevalence studies carried out, raises the question of the real etiologic agent of an unknown number of MSF or MSF-like cases that clinicians attend frequently in this area.

Acknowledgements This study has been supported by grants from Research Planning of Andalusia Government (Research Group CIV294). The authors thank Mr. Ernesto García-Márquez, EBD, for his help in dog sampling and Dr. Ricardo Oya, Research Services of Jaén University, for his technical assistance in sequencing. The experiments comply with the current laws of Spain and the European Union.

\section{References}

Azad AF, Beard CB (1998) Rickettsial pathogens and their arthropod vectors. Emerg Infect Dis 4:179-186

Bacellar F (1999) Ticks and spotted fever rickettsiae in Portugal. In: Brouqui DR (ed) Rickettsiae and rickettsial diseases at the turn of the third millennium. Elsevier, Paris, pp 423-427

Bartolomé J, Lorente S, Hernández-Pérez N, Martínez-Alfaro E, Marín-Ors A, Crespo MD (2005) Estudio clínico-epidemiológico de las rickettsiosis del grupo de las fiebres exantemáticas en Albacete. Enferm Infecc Microbiol Clin 23:194-196

Beati L, Raoult D (1993) Rickettsia massiliae sp. nov., a new spotted fever group Rickettsia. Int J Syst Bacteriol 43:839-840

Beati L, Keirans JE (2001) Analysis of the systematic relationships among ticks of the genera Rhipicephalus and Boophilus (Acari: Ixodidae) based on mitochondrial $12 \mathrm{~S}$ ribosomal DNA gene sequences and morphological characters. J Parasitol 87:32-48

Beati L, Roux V, Ortuño A, Castella J, Porta FS, Raoult D (1996) Phenotypic and genotypic characterization of spotted fever group Rickettsiae isolated from Catalan Rhipicephalus sanguineus ticks. J Clin Microbiol 34:2688-2694

Bernabeu-Wittel M, del Toro MD, Nogueras MM, Muniain MA, Cardeñosa N, Márquez FJ, Segura F, Pachón J (2006a) Seroepidemiological study of Rickettsia felis, Rickettsia typhi, and Rickettsia conorii infection among the population of southern Spain. Eur. J Clin Microbiol Infect Dis 25:375-381 
Bernabeu-Wittel M, del Toro MD, Nogueras MM, Muniain MA, Cardeñosa N, Márquez FJ, Segura F, Pachón J (2006b) Presence of human past infections due to the Bar29 rickettsial strain in Southern Spain. J Infect 52:e117-e119

Bernasconi MV, Casati S, Peter O, Piffaretti JC (2002) Rhipicephalus ticks infected with Rickettsia and Coxiella in Southern Switzerland (Canton Ticino). Infect Genet Evol 2:111-120

Bitam I, Parola P, Matsumoto K, Rolain JM, Baziz B, Boubidi SC, Harrat Z, Belkaid M, Raoult D (2006) First molecular detection of R. conorii, R. aeschlimannii, and R. massiliae in ticks from Algeria. Ann N Y Acad Sci 1078:368-372

Brouqui P, Parola P, Fournier PE, Raoult D (2007) Spotted fever rickettsioses in southern and eastern Europe. FEMS Immunol Med Microbiol 49:2-12

Cardeñosa N, Segura F, Raoult D (2003) Serosurvey among Mediterranean spotted fever patients of a new spotted fever group rickettsial strain (Bar29). Eur J Epidemiol 18:351-356

Cardeñosa N, Nogueras MM, Font B, Segura F, Muñoz T, Sanfeliu I (2006) Serological evidence of human infection with rickettsial strain Bar29 in Catalonia, northeastern Spain. Eur J Clin Microbiol Infect Dis 25:541-543

Eremeeva ME, Bosserman EA, Demma LJ, Zambrano ML, Blau DM, Dasch GA (2006) Isolation and identification of Rickettsia massiliae from Rhipicephalus sanguineus ticks collected in Arizona. Appl Environ Microbiol 72:5569-5577

Fernández-Soto P, Pérez-Sánchez R, Alamo-Sanz R, Encinas-Grandes A (2006a) Spotted fever group rickettsiae in ticks feeding on humans in northwestern Spain, is Rickettsia conorii vanishing? Ann N Y Acad Sci 1078:331-333

Fernández-Soto P, Pérez-Sánchez R, Díaz Martín V, Encinas-Grandes A, Alamo Sanz R (2006b) Rickettsia massiliae in ticks removed from humans in Castilla y León, Spain. Eur J Clin Microbiol Infect Dis 25:811-813

Guerrero A, Gimeno F, Colomina J, Molina M, Oteo JA, Cuenca M (2006) Low incidence of tick-borne rickettsiosis in a Spanish Mediterranean area. Ann N Y Acad Sci 1078:200-202

Herrero-Herrero JI, Ruiz-Beltrán R, Martín-Sánchez AM, García EJ (1989) Mediterranean spotted fever in Salamanca, Spain. Epidemiological study in patients and serosurvey in animals and healthy human population. Acta Trop 46:335-350
Márquez FJ, Muniain MA, Soriguer RC, Izquierdo G, RodríguezBaño J, Borobio MV (1998) Genotypic identification of an undescribed spotted fever group Rickettsia in Ixodes ricinus from southwestern Spain. Am J Trop Med Hyg 58:570-577

Matsumoto K, Brouqui P, Raoult D, Parola P (2005a) Experimental infection models of ticks of the Rhipicephalus sanguineus group with Rickettsia conorii. Vector Borne Zoonotic Dis 5: 363-372

Matsumoto K, Ogawa M, Brouqui P, Raoult D, Parola P (2005b) Transmission of Rickettsia massiliae in the tick, Rhipicephalus turanicus. Med Vet Entomol 19:263-270

Merino FJ, Nebreda T, Serrano JL, Fernández-Soto P, Encinas A, Pérez-Sánchez R (2005) Tick species and tick-borne infections identified in population from a rural area of Spain. Epidemiol Infect 133:943-949

Millán J, Ruiz-Fons F, Márquez FJ, Viota M, López-Bao JV, Paz Martín-Mateo M (2007) Ectoparasites of the endangered Iberian lynx Lynx pardinus and sympatric wild and domestic carnivores in Spain. Med Vet Entomol 21:248-254

Parola P, Paddock CD, Raoult D (2005) Tick-borne rickettsioses around the world, emerging diseases challenging old concepts. Clin Microbiol Rev 18:719-756

Psaroulaki A, Ragiadakou D, Kouris G, Papadopoulos B, Chaniotis B, Tselentis Y (2006) Ticks, tick-borne rickettsiae, and Coxiella burnetii in the Greek Island of Cephalonia. Ann N Y Acad Sci 1078:389-399

Raoult D, Roux V (1997) Rickettsioses as paradigms of new or emerging infectious diseases. Clin Microbiol Rev 10:694-719

Vitale G, Mansuelo S, Rolain JM, Raoult D (2006) Rickettsia massiliae human isolation. Emerg Infect Dis 12:174-175

Walker JB, Keirans JE, Horak IG (2000) The genus Rhipicephalus (Acari, Ixodoidea). A guide to the brown ticks of the world. Cambridge University Press, Cambridge

Zahler M, Filippova NA, Morel PC, Gothe R, Rinder H (1997) Relationships between species of the Rhipicephalus sanguineus group, a molecular approach. J Parasitol 83:302-306

Zhu Y, Fournier PE, Eremeeva M, Raoult D (2005) Proposal to create subspecies of Rickettsia conorii based on multi-locus sequence typing and an emended description of Rickettsia conorii. BMC Microbiol 5:11 